\title{
Influence of the calibration on experimental UV index at a midlatitude site, Granada (Spain)
}

\author{
M. Antón ${ }^{1,2}$, J. E. Gil ${ }^{1}$, A. Cazorla ${ }^{1}$, J. Fernández-Gálvez ${ }^{1}$, J. M. Vilaplana ${ }^{3}$, F. J. Olmo ${ }^{1}$, and L. Alados-Arboledas ${ }^{1}$ \\ ${ }^{1}$ Departamento de Física Aplicada, Universidad de Granada, Granada, Spain \\ ${ }^{2}$ Geophysics Centre of Evora, University of Evora, Evora, Portugal \\ ${ }^{3}$ Estación de Sondeos Atmosférico El Arenosillo, INTA, Huelva, Spain
}

Received: 28 July 2010 - Published in Atmos. Meas. Tech. Discuss.: 10 December 2010

Revised: 23 February 2011 - Accepted: 1 March 2011 - Published: 10 March 2011

\begin{abstract}
The ultraviolet index (UVI) is the most commonly used variable to inform about the level and potential harmful effect of ultraviolet (UV) radiation reaching the Earth's surface. This variable is derived from the output signal of UV radiometers applying conversion factors from calibration methods. This paper focused on the influence of the use of two of these methods (called one-step and two-steps methods) on the experimental UVI measured by a YES UVB-1 radiometer located in a midlatitude station, Granada (Spain) for the period 2006-2009. In addition, it also analyzes the deviation from the UVI values obtained when the manufacturer's calibration factors are applied. For this goal, a detailed characterization of the UVB-1 radiometer from the first Spanish calibration campaign of broadband UV radiometers at the "El Arenosillo" INTA station in 2007 was used. In addition, modeled UVI data derived from the LibRadtran/UVSPEC radiative transfer code are compared with the experimental values recorded at Granada for cloud-free conditions.

Absolute mean differences between measured and modeled UVI data at Granada were around 5\% using the onestep and two-steps calibration methods, indicating an excellent performance of these two techniques for obtaining UVI data from the UVB-1 radiometer. Conversely, the application of the manufacture's calibration factor produced a large overestimation ( $\sim 14 \%)$ of the UVI values, generating unreliable alarming high UVI data in summer. Thus, the number of days with an extreme erythemal risk (UVI higher than 10) increased up to $46 \%$ between May and September at Granada. This percentage reduced to a more reliable value of $3 \%$ when the conversion factors obtained with the two-steps calibration
\end{abstract}

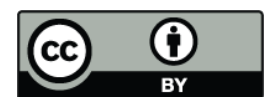

Correspondence to: M. Antón (mananton@unex.es) method are used. These results evidence the need for a sound calibration of the broadband UV instruments in order to obtain reliable measurements.

\section{Introduction}

The well-known depletion of the stratospheric ozone layer in the past decades causes concern about increasing ultraviolet (UV) radiation at the surface (UNEP, 2006). This radiation is key for several biological reactions in appropriate doses (Webb and Holick, 1988), but the overexposure can be very detrimental for humans, plants, animals and materials (Diffey, 1991, 2004).

The UV index (UVI) is a dimensionless magnitude commonly used to quantify the UV radiation levels with the objective of warning against their harmful effects on human health (Vanicek et al., 2000). The erythema or sunburn in human skin is the most usually adverse effect associated with UV radiation overexposure, with increasing awareness in society. This effect is generally quantified by weighing the solar UV radiation (280-400 $\mathrm{nm}$ ) with the erythemal spectral response (McKinlay and Diffey, 1987), resulting in the socalled UV erythemal radiation (UVER). The UVI is defined as 40 times UVER (expressed in $\mathrm{W} \mathrm{m}^{-2}$ ) according to the joint recommendation of the World Meteorological Organization (WMO), the World Health Organization (WHO), the United Nations Environmental Programme (UNEP), and the International Commission on Non-Ionizing Radiation Protection (ICNIRP) (WMO, 1998; WHO, 2002).

It is well documented that the UVI at the Iberian Peninsula reaches very high values (Martínez-Lozano et al., 2002; Marín et al., 2005; Antón et al., 2009a) due to the high solar

Published by Copernicus Publications on behalf of the European Geosciences Union. 
elevations reached at these latitudes throughout the year. This fact together with the changes in the population's habit associated with sun overexposure makes indispensable to obtain high-quality UVI measurements in this region in order to inform people and to reduce the risk of health damage. In this sense, the study by López-Abente et al. (2002) revealed an annually increase in melanoma (the most dangerous type of skin cancer) of about 8\% in Spain during the period 19521996.

The broadband UV radiometer is the instrument most widely used for measuring UVER due to its low cost and easy maintenance (WMO, 1996). Nevertheless, the relationship between the output signal (voltage) and the final product (UVER or UVI) is highly complex. Thus, these UV radiometers require an appropriate calibration procedure (Lantz et al., 1999; Leszczynski et al., 1998; Hülsen and Gröbner, 2007). Therefore, the intercomparison of broadband UV radiometers with respect to a reference spectroradiometer (traceable to international standards) provides a practical way for improving the accuracy and comparability of the measurements performed by different instruments (Leszczynski et al., 1995; Bais et al., 1999; Gröbner et al., 2007; Vilaplana et al., 2009).

In this context, it is highly interesting to study different calibration methods for measuring daily UVI in order to improve the accuracy of these values. The WMO adopted two methodologies for calibrating broadband UV radiometers: one-step and two-steps methods (Bais et al., 1999). In the one-step method, the calibration factor is directly derived from the comparison between the raw signal of the broadband UV radiometer and the erythemally integrated irradiance measured by a reference spectroradiometer. The two-steps method involves two stages; initially, the output signal of the broadband UV radiometer is compared with the effective irradiance from the reference spectroradiometer, then, the effective response values are converted to erythemal units.

In spite of its great interest, only a few studies have jointly analyzed both methods (Vilaplana et al., 2006). Hence, this paper focuses on the influence of using the manufacturer's calibration factor and the factors derived from the one-step and two-steps calibration methods in order to obtain experimental daily UVI at Granada (Southeastern Spain). For this goal, experimental UVI values were compared to UVI data derived from a multilayer radiative transfer model for cloudfree conditions. In addition, the evolution of the measured UVI values for all sky conditions was analyzed during the four year period (2006-2009).

The instrumentation and the data used in this paper are described in Sect. 2. Section 3 introduces the calibration methods used in this work to obtain experimental UVI values. Section 4 presents and discusses different methods for obtaining UVI and, finally, Sect. 5 summarizes the main conclusions.

\section{Data}

\subsection{Ground-based measurements}

The Atmospheric Physics Group (GFAT) of the University of Granada operates the radiometric station located on the rooftop of the Andalusian Center for Environmental Studies (CEAMA, $37.17^{\circ} \mathrm{N}, 3.61^{\circ} \mathrm{W}, 680 \mathrm{~m}$ a.s.1.).

A broadband UV radiometer model UVB-1 (manufactured by Yankee Environment System, YES) is installed at this station. The radiometer has a spectral range between 280 and $400 \mathrm{~nm}$, and a spectral sensitivity very close to the standard erythemal spectrum (McKinlay and Diffey, 1987). At operation, output voltages were sampled every ten seconds and recorded as 1-min average on a Campbell CR10X data acquisition system. This UVB-1 instrument took part in the first Spanish calibration campaign of ultraviolet broad-band radiometers at the "El Arenosillo" INTA station in Huelva (Spain), from 20 August to 15 September 2007. The campaign included spectral and angular characterization of the instruments, as well as the outdoor intercomparison to a wellcalibrated Brewer spectroradiometer (Vilaplana et al., 2009). Voltages provided by the UVB-1 instrument during the study period (2006-2009) were converted to UVER values applying calibration factors provided by the manufacturer and alternatively calibration coefficients were also derived from two calibration methods using data recorded during the El Arenosillo's campaign 2007. Several works have already shown the high stability of the YES UVB-1 radiometers if they are properly maintained, especially with regard to the periodic replacement of the desiccant (Bigelow et al., 1998).

Cloud cover was characterized in oktas (eighths of sky) derived from an All-Sky Imager developed by the GFAT team. It provides images of the whole sky dome in daytime, and it has been commonly used for atmospheric radiative transfer studies (Cazorla et al., 2008, 2009). The All-Sky Imager is a custom adaptation of a scientific CCD camera, using a digital color video camera mounted with a fish-eye lens $\left(180^{\circ}\right.$ FOV) pointing to the zenith. Additionally, the camera is environmentally protected and a solar-shadow system is used to avoid direct incidence of the Sun beam on the lens.

Aerosol information was retrieved from a CIMEL CE318 sun-photometer which is the standard instrument used in the AERONET network (Holben et al., 1998). The direct sun measurements at 340,380, 440, 500, 670, 870, and $1020 \mathrm{~nm}$ were used to retrieve aerosol optical depth (AOD) and Angstrom's coefficients following the methodology proposed by Alados-Arboledas et al. (2003a). Regularly, Langley plots at a high location in Sierra Nevada Range (2200 ma.s.l.) were performed for calibration purposes (Alcántara-Ruiz et al., 2004).

A Brewer MK-III double monochromator spectrophotometer was used as the reference instrument for calibrating the UVB-1 radiometer. This spectrophotometer was located at El Arenosillo (Huelva, Spain) and it provides spectral 
global UV irradiance between 290 and $363 \mathrm{~nm}$ with spectral resolution (FWHM) $\sim 0.6 \mathrm{~nm}$ and wavelength accuracy of $0.05 \mathrm{~nm}$. Besides the daily tests performed with the internal lamps, the Brewer spectrophotometer was periodically calibrated by comparison with a quartz-halogen NIST-traceable standard lamp (1000W DXW type) having an uncertainty of $1.56 \%$ at $250 \mathrm{~nm}$ and $1.12 \%$ at $350 \mathrm{~nm}$. This particular calibration transfer produces systematic uncertainties of $\pm 5 \%$ in the Brewer spectral irradiance measurements (Vilaplana, 2004). Moreover, data from the Brewer instrument used in this work were also regularly validated with the transportable Quality Assurance of Spectral Ultraviolet Measurements in Europe (QASUME) spectroradiometer (European irradiance reference) (Gröbner et al., 2006).

\subsection{UV index estimations}

The estimated values of UV index were derived from the LibRadtran software package whose main tool is the UVSPEC model, developed by Mayer and Kylling (2005).

The UVSPEC code consists of a multiple scattering radiative transfer model which computes plane-parallel radiative transfer in the Earth's atmosphere under cloudless or cloudy conditions. The pSeudospherical DIScreet Ordinate Radiative Transfer (SDISORT) method numerically solves the radiative-transfer equation in a vertically non-homogeneous plane-parallel atmosphere, running in 16 stream mode.

We implemented the UVSPEC model using standard profiles from the standard atmosphere midlatitude summer (afglms), and midlatitude winter (afglmw) which comprise 50 levels between 0 and $120 \mathrm{~km}$ (Anderson et al., 1986). In all simulations, cloud-free conditions were assumed, with a surface UV albedo of 0.035 . For aerosols, the appropriated spring-summer and fall-winter profiles given by Shettle (1989) were used. We chose an urban aerosol type and the impact of the aerosol loading in the boundary was expressed by means of the Angstrom's coefficients $(\beta$ and $\alpha$ ) retrieved by the Cimel sun-photometer (see Sect. 2.1). In addition, we set to constant values of 0.9 and 0.7 for the single scattering albedo and the asymmetry factor, respectively. These values are set based on averages of the Cimel sun-photometer measurements at $440 \mathrm{~nm}$ obtained during August 2003 at Granada (Lyamani et al., 2006).

The model uses as input the daily total ozone column (TOC) provided by the Ozone Monitoring Instrument (OMI) (Levelt et al., 2006). The ozone profile was scaled according to these daily TOC values. The OMI data used in this work were retrieved from the OMI-TOMS algorithm which is based on the long-standing NASA TOMS V8 retrieval algorithm (Bhartia and Wellemeyer, 2002). In general, there is an excellent agreement between OMI-TOMS and ground-based measurements. The work by Antón et al. (2009b) reported that the OMI-TOMS data are on average a mere $2.0 \%$ lower than Brewer TOC measurements in five Spanish ground-based stations. Finally, the daily UV Index

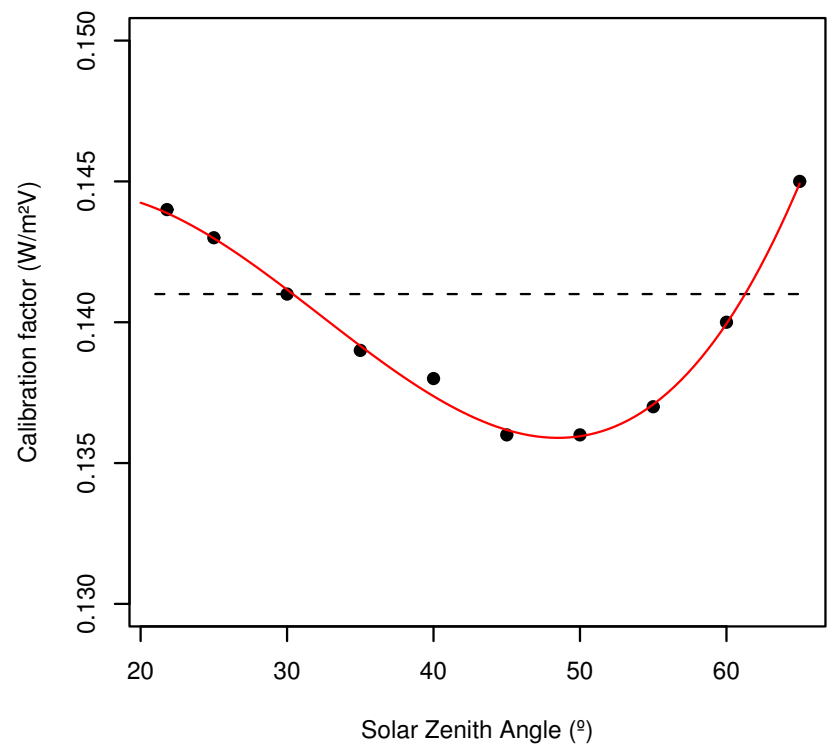

Fig. 1. Dependence of the calibration factors provided by the manufacturer (in black) on the solar zenith angles below $65^{\circ}$. The red line corresponds to the polynomial function given by the expression 1 . The dashed line represents the fixed value of $0.141 \mathrm{~W} \mathrm{~m}^{-2} \mathrm{~V}^{-1}$ proposed by the manufacturer when the dependence on solar zenith angle is not utilized.

corresponding to local solar noon (minimum solar zenith angle, SZA) was estimated using all available information.

\section{Calibration procedures}

\subsection{Manufacturer}

The calibration factors supplied by Yankee E. S. for the UVB-1 radiometer are a function of the SZA. Thus, it is possible to obtain a polynomial function by means of a linear regression analysis from the ten values of the calibration factors provided by the manufacturer for SZA between $22^{\circ}$ and $65^{\circ}$. In this sense, we proposed the following polynomial third-order dependence between $C F$ values and the SZA:

$$
\begin{aligned}
C F(\mathrm{SZA}) & =0.136+0.019 \times \mathrm{SZA}-4.9 \times 10^{-5} \\
& \times \mathrm{SZA}^{2}+5.1 \times 10^{-7} \times \mathrm{SZA}^{3}
\end{aligned}
$$

where $C F$ is the calibration factor in $\mathrm{W} \mathrm{m}^{-2} \mathrm{~V}^{-1}$ and SZA is the solar zenith angle in degrees.

Figure 1 shows the dependence of the ten calibration factors (in black) provided by the manufacturer on the SZA values below $65^{\circ}$. The red line corresponds to the polynomial function given by the above expression. From this function, the sensor output in volts can be multiplied by $C F$ in order to obtain the "manufacturer" UVER values. In this figure, the dashed line represents the fixed value of $0.141 \mathrm{~W} \mathrm{~m}^{-2} \mathrm{~V}^{-1}$ proposed by the manufacturer when the dependence on SZA is not utilized. 

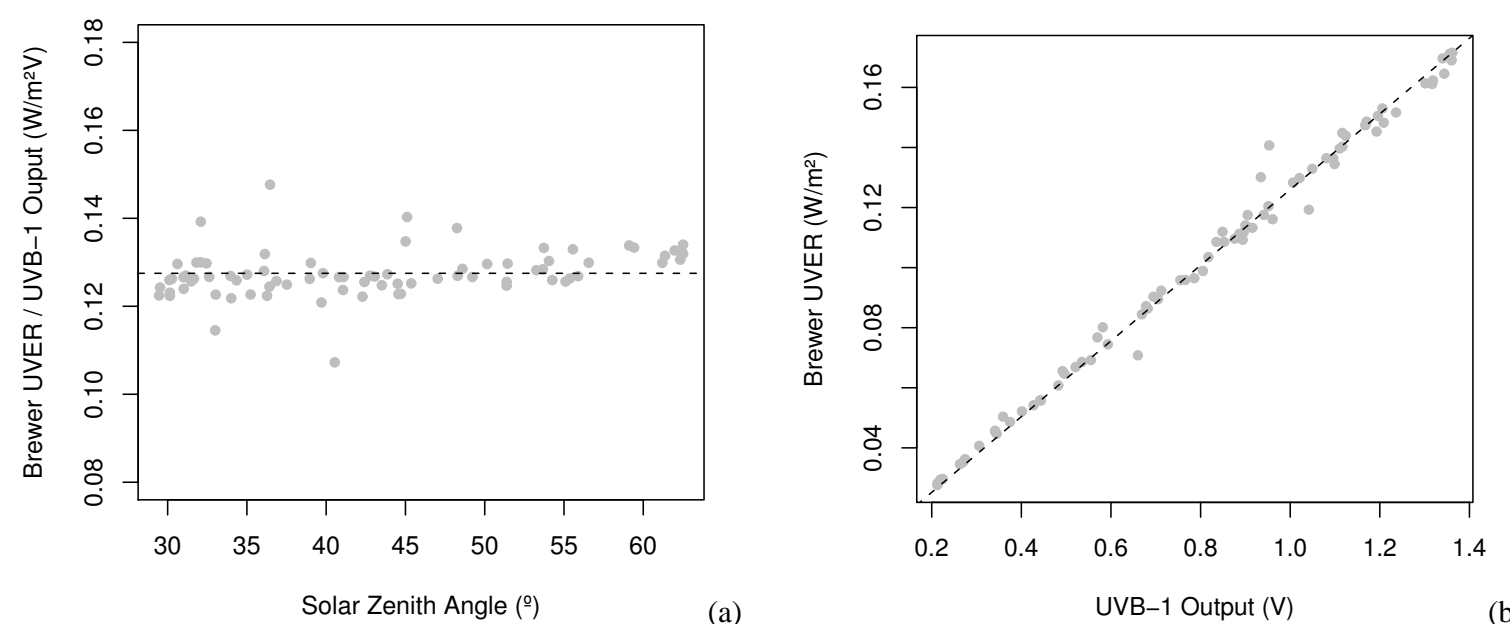

Fig. 2. (a) The ratio between the erythemally integrated irradiance given by the Brewer spectroradiometer and the YES UVB-1 radiometer output voltage as a function of the solar zenith angle during the Arenosillo's campaign 2007. The horizontal line represents the mean ratio $\left(0.1275 \mathrm{~W} \mathrm{~m}^{-2} \mathrm{~V}^{-1}\right)$. (b) relationship between the Brewer erythemally integrated irradiance and the UVB-1 output voltage for SZA smaller than $65^{\circ}$ together with the regression line corresponding to the first-order model.

\subsection{One-step method}

To our knowledge, only two versions of the one-step method can be found in the literature. One of them is based on the ratio between broadband radiometer's measurements and integrated spectrophotometer's values (Leszczynski et al., 1998; Bais et al., 1999). The another one consists of a first-order linear dependence between the measurements given by the two instruments (Bodhaine et al., 1998; Grainger et al., 1993; Nunez et al., 1997). The work of Cancillo et al. (2005) compared the performance of these two procedures and proposed a second-order dependence in order to improve the calibration performance for high solar elevations.

This method needs simultaneously records of the UVB-1 radiometer and Brewer spectrophotometer. For this goal, the UVB-1 voltages during the Arenosillo's campaign 2007 (one measurement every $10 \mathrm{~s}$ ) were averaged along the one minute period which takes each Brewer scan between $310 \mathrm{~nm}$ and $324 \mathrm{~nm}$ (range of wavelengths where the UV spectral irradiance weighted by the CIE response function present higher values). Figure 2a shows the ratio between the erythemally integrated irradiance given by the Brewer spectroradiometer and the UVB-1 radiometer output voltage as a function of the SZA during the calibration campaign. The horizontal line represents the mean ratio $\left(0.1275 \pm 0.0006 \mathrm{~W} \mathrm{~m}^{-2} \mathrm{~V}^{-1}\right)$, which is taken by the ratio method as the calibration factor. For calculating this mean ratio, we have selected radiative and voltage values for SZA less than $65^{\circ}$ and cloud-free conditions in order to minimize systematic errors attributed to deviations of the angular response of the UVB-1 radiometer.

The relationship between the Brewer erythemally integrated irradiance and the UVB-1 output voltage for SZA smaller than $65^{\circ}$ is shown in the Fig. $2 b$ together with the regression line corresponding to the first-order model. The slope of this line $\left(0.1260 \pm 0.0005 \mathrm{~W} \mathrm{~m}^{-2} \mathrm{~V}^{-1}\right)$ is the calibration factor derived from the linear regression analysis.

The calibration factors calculated by this method are about $10 \%$ lower than the fixed value provided by the manufacturer. This result is in agreement with the calibration campaign of broadband UV radiometers performed in Thessalonica in 1999 (Bais et al., 1999) which showed differences up to $20 \%$ between the manufacturer's calibration factors for UVB-1 instruments and the individual factors derived from this campaign. These differences could be related to uncertainties in the spectral UV measurements recorded by the reference spectrophotometer used by the manufacturer and/or the method utilized to derived its calibration factor. This fact shows evidence that each instrument needs a sound calibration in order to obtain reliable UV measurements.

\subsection{Two-steps method}

This method requires the laboratory characterization of the spectral and angular responses of the broadband UV radiometers. The whole description of the two-steps method is beyond the scope of this paper, but it can be found in the works of Webb et al. (2006), Hülsen and Gröbner (2007), Vilaplana et al. (2009) and Antón et al. (2011). These reference works proposed the following expression to convert the raw signal of broadband UV radiometer into erythematic units $\left(\mathrm{W} \mathrm{m}^{-2}\right)$ :

$E_{\mathrm{CIE}}=\left(U-U_{\text {offset }}\right) C f_{n}(\mathrm{SZA}, \mathrm{TOC})$ Coscor (SZA)

where:

$E_{\mathrm{CIE}}$ is eryhtemal $\mathrm{UV}$ irradiance in $\mathrm{W} \mathrm{m}^{-2}$.

$U$ is the measured electrical signal by the broadband radiometer in $\mathrm{V}$.

$U_{\text {offset }}$ is the electrical offset for dark conditions in V. 

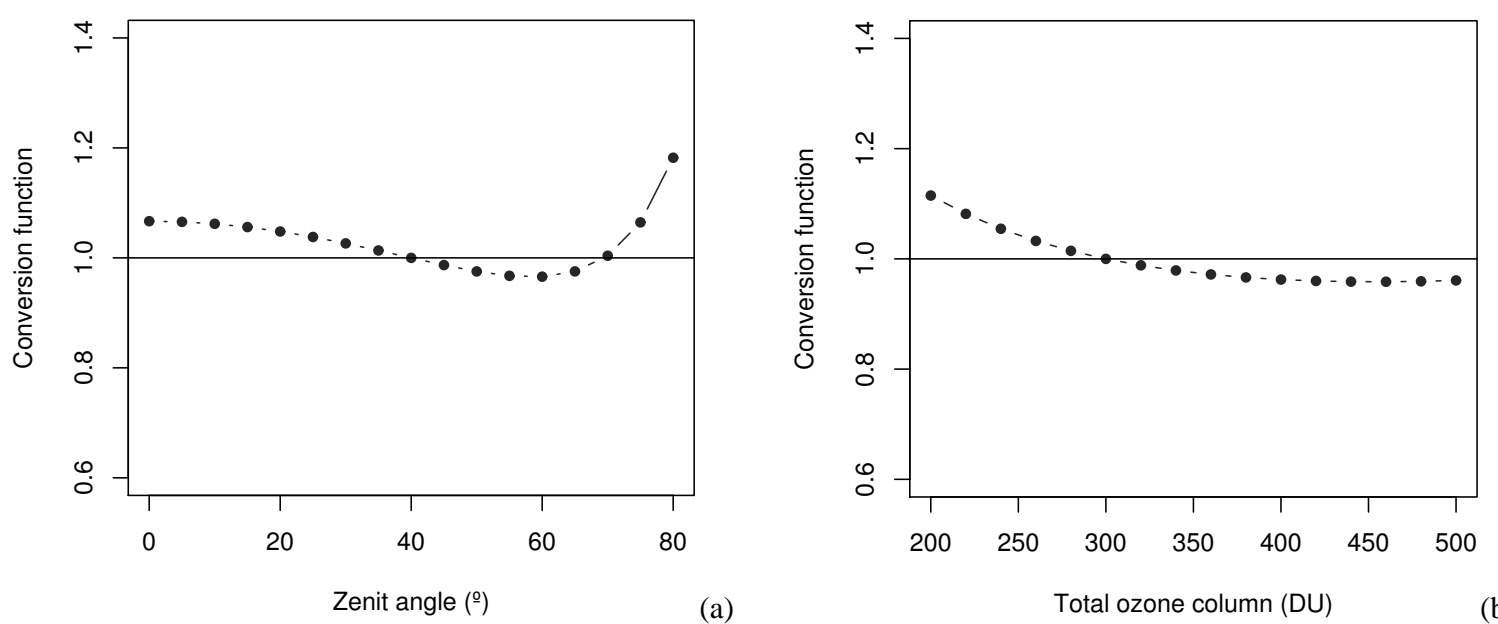

Fig. 3. (a) Variation of the normalized conversion function with respect to the solar zenith angle, for a constant total ozone column of 300 DU. (b Variation of the normalized conversion function with respect to the total ozone column, for a constant solar zenith angle of $40^{\circ}$.

$C$ is the absolute calibration coefficient in $\mathrm{W} \mathrm{m}^{-2} \mathrm{~V}^{-1}$. $f_{n}$ (SZA,TOC) is the conversion function (unitless). Coscor (SZA) is the cosine correction function in dependence of the SZA (unitless).

Here, we present the results obtained for our YES UVB-1 radiometer from El Arenosillo campaign 2007. The absolute calibration coefficient is obtained as the averaged ratio between the output voltage of the UVB-1 radiometer and the effective UV irradiance calculated by the integration of the Brewer spectral irradiance weighted by the actual spectral response of the broadband radiometer which is characterized indoor, in the laboratory. Only values for SZA lower than $65^{\circ}$ were considered for the calculation of this absolute calibration coefficient. The value obtained for our UVB-1 radiometer was $0.1150 \pm 0.0062 \mathrm{~W} \mathrm{~m}^{-2} \mathrm{~V}^{-1}$.

The conversion function transforms the effective irradiance to erythemally weighted irradiance. Thus, this function informs about the deviation between the actual spectral response of the UVB-1 radiometer and the standard erythemal action spectrum. It can be expressed as a look up table derived from a radiative transfer model (Vilaplana et al., 2009). This table depends on the parameters with major spectral influence in the UV range: the solar zenith angle and the total ozone column. Figure $3 \mathrm{a}$ shows the variation of the normalized conversion function with respect to SZA, for a constant TOC value of $300 \mathrm{DU}$. When SZA changes from $0^{\circ}$ to $80^{\circ}$, the relative differences in the conversion function are less than $20 \%$. In addition, Fig. $3 \mathrm{~b}$ shows the variation of the normalized conversion function with respect to TOC for a constant SZA value of $40^{\circ}$. The relative difference between the value of the conversion function for $200 \mathrm{DU}$ and the value for $500 \mathrm{DU}$ is around $14 \%$.

Finally, the cosine correction function informs about the cosine error; the deviation that the broadband UV instrument experiences with respect to the ideal angular response. This function is also derived from indoor measurements in the laboratory. Figure 4 shows the variation of the cosine correction function of the UVB-1 radiometer with respect to the SZA. It is shown that the angular correction of this instrument is around $5 \%$ for SZA values smaller than $20^{\circ}$, and it is between $10 \%$ and $15 \%$ for SZA valued higher than $50^{\circ}$.

\section{Experimental UV index}

The daily UV index obtained applying the manufacturer coefficients and the one-step and two-steps calibration methods are compared. To analyze the differences between the experimental UVI obtained under different calibration methods, we use, as reference, the UVI derived from the LibRadtran/UVSPEC radiative transfer code (see Sect. 2.2). In general, the daily UVI estimations provided by models are calculated for solar noon, thus in order to make a comparison with experimental UVI values, these have to be also obtained at solar noon. In addition, since cloud-free sky conditions are especially interesting cases for the comparison with radiative transfer model results, the relative differences between the different calibration methods were obtained for those particular conditions. The selection of the cloud-free conditions was performed by means of the All-Sky Imager (see Sect. 2.1). Thus, days with zero oktas at solar noon were classified as cloud-free cases. The percentage of days selected with this restrictive threshold at Granada for period 2006-2007 was 45\%, which indicates the high number of cloud-free situations in South Spain.

In order to compare the UVSPEC estimations with experimental results, three linear regressions were performed between UVI estimations and the experimental values obtained applying the manufacture's factor and the two calibration procedures. The slopes and the statistical parameters 


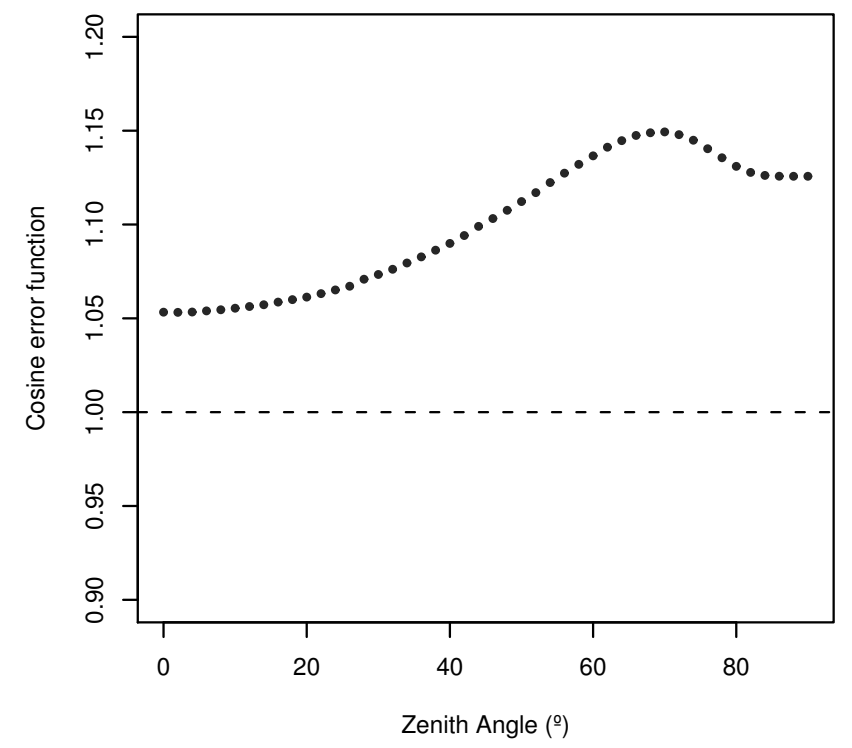

Fig. 4. Variation of the cosine correction function of the YES UVB1 radiometer with respect to the solar zenith angle.

obtained in the three regression analyses are shown in Table 1. Correlation between the measured and modeled UVI data sets are significantly high for the three datasets $\left(R^{2} \sim 0.98\right)$, with a significantly small spread (RMSE $\sim 8 \%$ ). It can be seen that the slopes are very close to 1 for the experimental values derived from the one-step and two-steps methods. Table 1 presents also the MBE (mean bias error) and the MABE (mean absolute bias error) parameters obtained for the three data sets. These statistics are obtained by the following expressions:

$\mathrm{MBE}=100 \times \frac{1}{N} \sum_{i=1}^{N} \frac{\mathrm{UVI}_{\text {measured }}-\mathrm{UVI}_{\text {modelled }}}{\mathrm{UVI}_{\text {modelled }}}$

$\mathrm{MABE}=100 \times \frac{1}{N} \sum_{i=1}^{N} \frac{\left|\mathrm{UVI}_{\text {measured }}-\mathrm{UVI}_{\text {modelled }}\right|}{\mathrm{UVI}_{\text {modelled }}}$

The small positive value $(\sim 1 \%)$ of the MBE for the onestep and two-steps methods indicates that the experimental UVI data obtained by these calibration techniques present a slight overestimation of the UVI estimations. In addition, the MABE parameters for these two calibration techniques present values around 5\% which indicates a good agreement between measured and modeled UVI data at Granada. This result agrees with other inter-comparison works using the $\mathrm{Li}$ bRadtran/UVSPEC code and experimental data (e.g., Mayer et al., 1997; Kylling et al., 1998; de Backer et al., 2001). The uncertainty of MBE and MABE parameters given by their standard error is always lower than $0.7 \%$, indicating the high statistical significance of the reported values. The scatter plot presented in Fig. 5 (the solid line is the zero bias line, unit slope) confirms this high degree of proportionality. All these
Table 1. Parameters obtained in the correlation between measured and modeled UVI data. Experimental measurements are derived from manufacturer factor, and one-step and two-steps methods, while modeled data are inferred from LibRadtran/UVSPEC code. The parameters are as follows: the slope of the regression, the coefficients of correlation $\left(R^{2}\right)$, the root mean square errors (RMSE), the mean bias error (MBE), and the mean absolute bias error (MABE). The relative differences are calculated as measured minus modeled, divided by the modeled UVI data.

\begin{tabular}{lccccr}
\hline & Slope & $R^{2}$ & $\begin{array}{c}\text { RMSE } \\
(\%)\end{array}$ & \multicolumn{1}{c}{$\begin{array}{c}\text { MBE } \\
(\%)\end{array}$} & \multicolumn{1}{c}{$\begin{array}{c}\text { MAB } \\
(\%)\end{array}$} \\
\hline Manufacturer & $0.85 \pm 0.01$ & 0.98 & 7.9 & $+13.5 \pm 0.8$ & $14.2 \pm 0.7$ \\
One-step method & $0.99 \pm 0.01$ & 0.98 & 8.4 & $+1.3 \pm 0.7$ & $5.6 \pm 0.6$ \\
Two-steps method & $0.99 \pm 0.01$ & 0.99 & 7.8 & $+1.3 \pm 0.6$ & $5.1 \pm 0.5$ \\
\hline
\end{tabular}

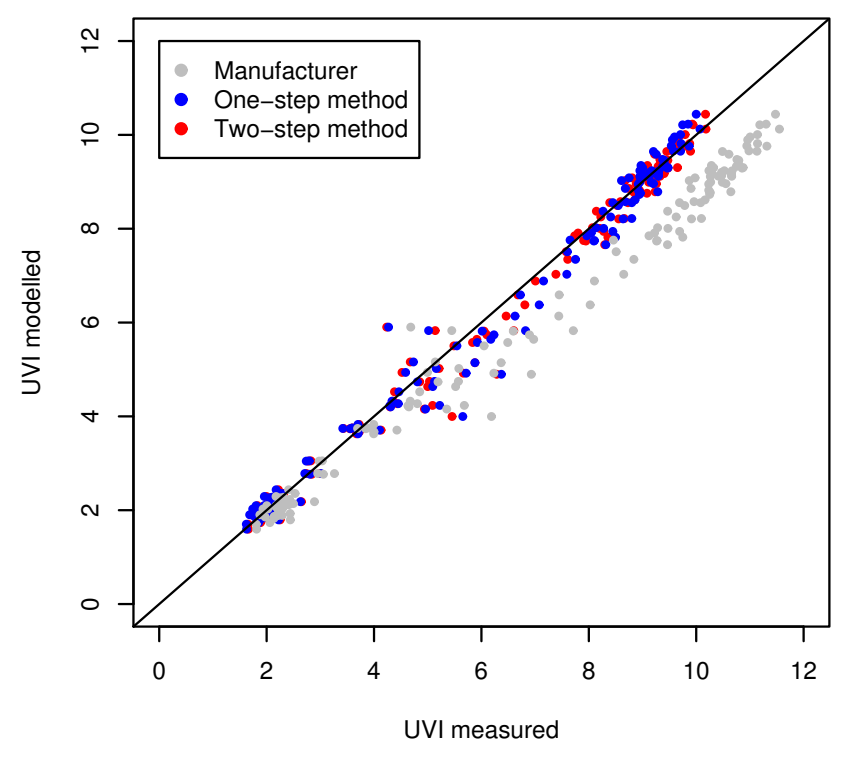

Fig. 5. Relationship between UVI estimations derived from LibRadtran/UVSPEC model and experimental UVI data obtained applying the manufacture's factor and the two calibration procedures. The solid line is the zero bias line, unit slope.

results show the excellent effectiveness of the two calibration methods applied to obtain UVI information from YES UVB1 records.

On the other hand, Fig. 5 shows that the UVI data obtained applying the calibration factors provided by the manufacturer clearly overestimate the UVI derived from the UVSPEC model (the slope of the regression line is 0.85 ). This behavior is corroborated by the high positive value $(\sim 14 \%)$ of the MBE parameter. Moreover, the MABE parameter presents a similar absolute value which reveals the presence of a notable bias with a small statistical spread. Figure 5 also shows that this bias is lower for small UVI values than for high UVI values. Thus, when the relative differences between measured and modeled UVI are plotted as function of SZA (not 
shown), it can be seen a clear dependence between these two variables. We obtain a MBE value of $9 \%$ for SZA greater than $50^{\circ}$ (small UVI values), and a value of $16 \%$ for SZA smaller than $30^{\circ}$ (high UVI values). This behaviour is mainly related to the calibration curve given by the manufacturer (Fig. 1) which shows that for small SZA values the manufacturer's factors (between 0.140 and 0.145 ) differs significantly with respect to the calibration factors given by the first-step method (0.1275) and the absolute calibration coefficient derived from the two-step method (0.1150). All these results show the unreliability of the calibration factors provide by the manufacturer, revealing the great importance of the individual calibration of the broadband UV radiometers. Therefore, the general calibration factors supplied by the manufacturer should not be applied for broadband UV radiometers corresponding to the same model and manufacturer.

The relative differences between the experimental UVI values derived from the one-step and two steps calibration methods are small (lower than 4\%) for the YES UVB-1 broadband radiometer installed at Granada. This result is related to the high solar elevations recorded at solar noon in South Spain (SZA lower than $65^{\circ}$ ). Thus, it is expected that the differences between UVI values obtained by the one-step and two steps methods could increase for instruments located at higher latitudes. When all information is available, the use of the two-steps method is recommended by several organizations responsible for calibration protocols of broadband UV radiometers because of its higher accuracy (Bais et al., 1999; Webb et al., 2003).

Figure 6 shows the evolution of the daily UVI at Granada during four years (2006-2009) under all sky conditions using the two-steps calibration method and the manufacturer's calibration factors. These daily values have been obtained applying the standard definition proposed by the WHO (2002). According to this proposal, the daily UV Index corresponds to the daily maximum $30 \mathrm{~min}$ averaged UVER measured at the earth's surface. It can be seen that the annual solar cycle (driven by astronomical factors) and the total ozone annual cycle explain the sinusoidal evolution of the UVI values. In addition, the figure shows significant day-to-day variability which is mainly associated with changes in the cloud cover (Alados-Arboledas et al., 2003b). These short-term UVI changes are also affected by the day-to-day fluctuations of the aerosol load (di Sarra et al., 2002) and the total ozone column (Antón et al., 2008).

Category labels associated with numerical interval of the UVI are a practice tool to inform people about the erythemal risk (sunburn of the human skin). In this sense, COST713 Action "Long term changes and climatology of UV radiation over Europe" established a universal category with intervals ranging from low erythemal risk ( $0-3)$, moderate (4-6), high (7-9) and extreme (>10) (Vanicek et al., 2000). Days classified as cases with high and extreme erythemal risk correspond to $22.1 \%$ and $1.2 \%$ of all cases, respectively, when the two-steps method is applied to the calibration of the

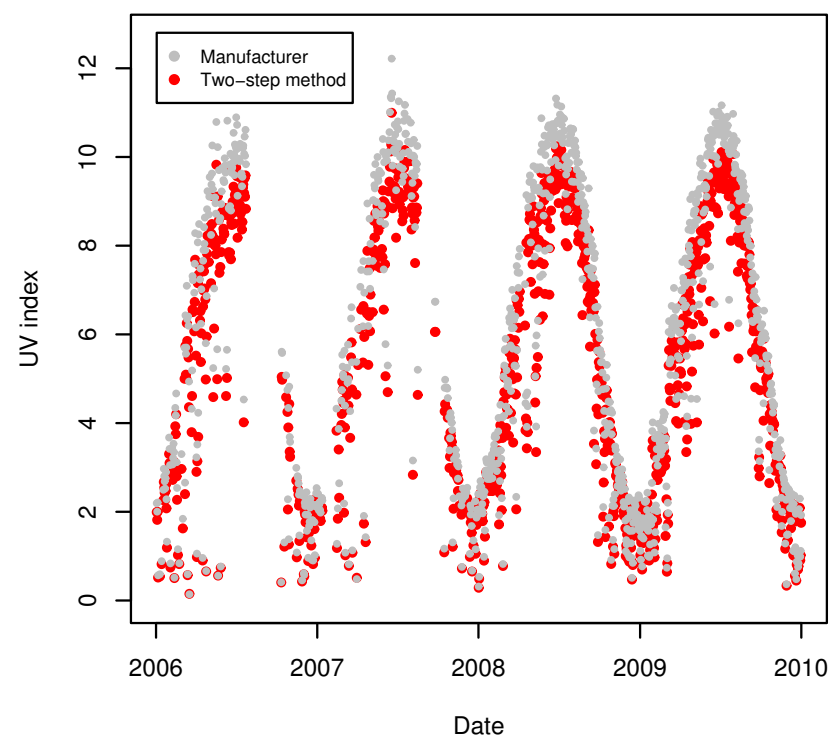

Fig. 6. Temporal evolution of the daily UVI at Granada during four years (2006-2009) using the two-steps calibration method and the manufacturer's calibration factors.

UVB-1 radiometer installed at Granada. This result agrees with Marín et al. (2005) who found high erythemal risk between $18 \%$ and $25 \%$ of all days at nine ground-based stations located in East Spain. These cases are mainly recorded between the late spring and the beginning of autumn (many cloud-free days). Thus, if the analysis is limited between May and September, then the $46.7 \%$ and $2.8 \%$ of all cases in these months correspond to high and extreme erythemal risk at Granada.

The UVI values obtained applying the manufacturer's factors clearly overestimate the real UVI data at Granada (Fig. 6). Thus, using this calibration, days classified as extreme erythemal risk correspond to $46 \%$ of all cases measured between May and September. Therefore, the use of unsuitable calibration factors could generate alarming high UVI values. These results enhance the interest of an appropriate characterization of the broadband UV radiometer in order to report reliable UVI values.

\section{Conclusions}

Some important conclusions may be drawn from this work. First of all, this study has shown that the actual conversion factor corresponding to the YES UVB-1 instrument localized at Granada is around 10\% smaller than the calibration factor supplied by the manufacturer. This result underlines the importance of an accurate characterization of broadband UV radiometers in order to obtain highly reliable UV irradiance data.

Two calibration techniques (one-step and two-steps) have been used in this work for determining the calibration factors 
of our broadband UV radiometer. From these conversion factors, the experimental daily UVI values at Granada have been reported for the period 2006-2009. The comparison between these experimental values and the estimations derived from a radiative transfer model confirm that the UVI values derived from the manufacturer's calibration is inadequate, generating alarming high UVI values in summer. In contrast, both one-step and two-steps methods provide reliable data with mean values of the relative differences between measured and modeled UVI data around 5\%. Finally, although two-steps method is recommended by several organizations because of its higher accuracy, the simpler one-step method provide very similar experimental UVI data at Granada (relative differences lower than $4 \%$ ) due to the high solar elevations reached in this location throughout the year.

Acknowledgements. Authors thank the organizers (El Arenosillo/INTA team and AIRE/UEx team) of the first Spanish inter-comparison campaign of broadband UV instruments at El Arenosillo station in 2007. Manuel Antón thanks Ministerio de Ciencia e Innovación and Fondo Social Europeo for the award of a postdoctoral grant (Juan de la Cierva). This work was partially supported by the Andalusian Regional Government through projects P08-RNM-3568 and P10-RNM-6299, the Spanish Ministry of Science and Technology through projects CGL2010-18782 and CSD2007-00067.

Edited by: J. Joiner

\section{References}

Alados-Arboledas, L., Lyamani, H., and Olmo, F. J.: Aerosol size properties at Armilla, Granada (Spain), Q. J. Roy. Meteor. Soc., 129, 1395-1413, 2003a.

Alados-Arboledas, L., Alados, I., Foyo-Moreno, I., Olmo, F. J., and Alcántara, A.: The influence of clouds on surface UV erythemal irradiance, Atmos. Res., 66, 273-290, 2003b.

Alcántara-Ruiz, A., Olmo, F. J., and Alados-Arboledas, L.: Langley calibrations of sunphotometer at Sierra Nevada, Granada, Spain, Optica pura y Aplicada, 37, 3263-3269, 2004.

Anderson, G., Clough, S., Kneizys, F., Chetwynd, J., and Shettle, E.: AFGL atmospheric constituent profiles $(0-120 \mathrm{~km})$, Tech. Rep. AFGL-TR-86-0110, Air Force Geophys. Lab., Hanscom Air Force Base, Bedford, Mass., 1986.

Antón, M., Serrano, A., Cancillo, M. L., and García, J. A.: Total ozone and solar erythemal irradiance in southwestern Spain: Day-to-day variability and extreme episodes, Geophys. Res. Lett., 35, L20804, doi:10.1029/2008GL035290, 2008.

Antón, M., Serrano, A., Cancillo, M. L., and García, J. A.: Experimental and forecasted values of the UV index in South-Western Spain, J. Geophys. Res., 114, D05211, doi:10.1029/2008JD011304, 2009a.

Antón, M., López, M., Vilaplana, J. M., Kroon, M., McPeters, R., Bañón, M., and Serrano, A: Validation of OMI-TOMS and OMIDOAS total ozone column using five Brewer spectroradiometers at the Iberian Peninsula, J. Geophys. Res., 114, D14307, doi:10.1029/2009JD012003, 2009b.

Antón, M., Serrano, A., Cancilllo, M. L., and Vilaplana, J. M.: Quality assurance of broadband erythemal radiometers at the
Extremadura UV Monitoring Network (Southwestern Spain), Atmos. Res., 100, 83-92, doi:10.1016/j.atmosres.2010.12.029, 2011.

Bais, A., Topaloglou, C., Kazadtzis, S., Blumthaler, M., Schreder, J., Schmalwieser, A., Herniques, D., and Janouch, M.: Report of the LAP/COST/WMO intercomparison of erythemal radiometers, Technical Report TD 1051, WMO/GAW, 1999.

Bhartia, P. K. and Wellemeyer, C.: TOMS-V8 total $\mathrm{O}_{3}$ algorithm, in: OMI Algorithm Theoretical Basis Document, vol. II, OMI Ozone Products, edited by: Bhartia, P. K., available at: http://eospso.gsfc.nasa.gov/eos_homepage/for_scientists/ atbd/index.php, last access: 1 June 2010, NASA Goddard Space Flight Cent., Greenbelt, Md., 15-31, 2002.

Bigelow, D. S., Slusser, J. R., Beaubien, A. F., and Gibson, J. H.: The USDA Ultraviolet Radiation Monitoring Program, B. Am. Meteorol. Soc., 79, 601-615, 1998.

Bodhaine, B. A., Dutton, E. G., McKenzie, R. L., and Johnston, P. V.: Calibrating broad-band UV instruments: Ozone and solar zenith angle dependence, J. Atmos. Ocean. Tech., 15, 916-926, 1998.

Cancillo, M. L., Serrano, A., Antón, M., García, J. A., Vilaplana, J. M., and de la Morena, B.: An improved outdoor calibration procedure for broadband ultraviolet radiometers, Photochem. Photobiol., 81, 860-865, 2005.

Cazorla, A., Olmo, F. J., and Alados-Arboledas, L.: Development of a sky imager for cloud cover assessment, J. Opt. Soc. Am. A, 25(1), 29-39, 2008.

Cazorla, A., Shields, J. E., Karr, M. E., Olmo, F. J., Burden, A., and Alados-Arboledas, L.: Technical Note: Determination of aerosol optical properties by a calibrated sky imager, Atmos. Chem. Phys., 9, 6417-6427, doi:10.5194/acp-9-6417-2009, 2009.

de Backer, H., Koepke, P., Bais, A., de Cabo, X., Frei, T., Gillotay, D., Haite, C., Heikkilä, A., Kazantzidis, A., Koskela, T., Kyrö, E., Lapeta, B., Lorente, J., Masson, K., Mayer, B., Plets, H., Redondas, A., Renaud, A., Schauberger, G., Schmalwieser, A., Schwander, H., and Vanicek, K.: Comparison of measured and modelled uv indices for the assessment of health risks, Meteorol. Appl., 8, 267-277, 2001.

di Sarra, A., Cacciani, M., Chamard, P., Cornwall, C., DeLuisi, J. J., Di Iorio, T., Disterhoft, P., Fiocco, G., Fua, D., and Monteleone, F.: Effects of desert dust and ozone on the ultraviolet irradiance at the Mediterranean island of Lampedusa during PAUR II, J. Geophys. Res., 107(D18), 8135, doi:10.1029/2000JD000139, 2002.

Diffey, B.: Solar ultraviolet radiation effects on biological systems, Phys. Med. Biol., 36, 299-328, 1991.

Diffey, B.: Climate change, ozone depletion and the impact on ultraviolet exposure of human skin, Phys. Med. Biol., 49, R1-R11, 2004.

Grainger, R. G., Basher, R. E., and McKenzie, R. L.: UV-B Robertson-Berger meter characterization and field calibration, Appl. Optcs, 32, 343-349, 1993.

Gröbner, J., Blumthaler, M., Kazadzis, S., Bais, A., Webb, A., Schreder, J., Seckmeyer, G., and Rembges, D.: Quality assurance of spectral solar UV measurements: result from $25 \mathrm{UV}$ monitoring sites in Europe, 2002 to 2004, Metrologia, 43, S66-S71, 2006.

Gröbner, G., Hülsen, G., Vuilleumier, L., Blumthaler, M, Vilaplana, J. M., Walker, D., and Gil, J. E.: Report of the PMOD/WRC-COST Calibration and Intercomparison 
of Erythemal radiometers Davos, available at: http: //i115srv.vu-wien.ac.at/uv/COST726/COST726_Dateien/ Results/PMOD_WRC_COST726_campaign_2006_R.pdf, last access: 1 June 2010, Switzerland, 28 July-23 August, 2007.

Holben, B. N., Eck, T. F., Slutsker, I., Tanré, D., Buis, J. P., Setzer, A., Vermote, E., Reagan, J. A., Kaufman, Y. J., Nakajima, T., Lavenu, F., Jankowiak, I., and Smirnov, A.: AERONET - A federated instrument network and data archive for aerosol characterization, Remote Sens. Environ., 66(1), 1-16, 1998.

Hülsen, G. and Gröbner, G.: Characterization and calibration of ultraviolet broadband radiometersmeasuring erythemally weighted irradiance, Appl. Optics, 46, 5877-5886, 2007.

Kylling, A., Bais, A. F., Blumthaler, M., Schreder, J., Zerefos, C. S., and Kosmidis, E.: Effect of aerosols on solar UV irradiances during the photochemical activity and solar ultraviolet radiation campaign, J. Geophys. Res., 103, 26051-26060, 1998.

Lantz, K., Disterhoft, P., DeLuisi, J. J., Early, E., Thompson, A., Bigelow, D., and Slusser, J.: Methodology for deriving clear-sky erythemal calibration factors for UV broadband radiometers of the U.S. central UV calibration facility, J. Atmos. Ocean. Tech., 16, 1736-1752, 1999.

Leszczynski, K., Jokela, K., Ylianttila, L., Visuri, R., and Blumthaler, M.: Report of the WMO/STUK Intercomparison of Erythemally- Weighted Solar UV Radiometers, Spring/Summer 1995, World Meteorological Organization (WMO), WMO/GAW Rep. 112, 1995.

Leszczynski, K., Jokela, K., Ylianttila, L., Visuri, R., and Blumthaler, M.: Erythemally weightedradiometers in solar UV monitoring: results from the WMO/STUK intercomparison, Photochem. Photobiol., 67(2), 212-221, 1998.

Levelt, P. F., Hilsenrath, E., Leppelmeier, G. W., Van den Oord, G. H. J., Bhartia, P. K., Tamminen, J., De Haan, J. F., and Veefkind, J. P.: The ozone monitoring instrument, IEEE T. Geosci. Remote, 44, 1093-1101, 2006.

López-Abente, G., Pollán, M., Aragonés, N., Pérez, B., Llácer, A., Pérez, J., Medrano, M. J., Boix, R., Diez, M., González, P., Navas, A., Almazán, J., Jiménez, M. T., and de Pedro, J.: Tendencias de la mortalidad en España, 1952-1996, ISBN: 84688-0730-3, http://www2.uca.es/hospital/TM/portada.html, last access: 1 June 2010, Ed. Centro Nacional de Epidemiología, Madrid, Spain, 2002.

Lyamani, H., Olmo, F. J., Alcántara, A., and Alados-Arboledas, L.: Atmospheric aerosols during the 2003 heat wave in southeastern Spain II: Microphysical columnar properties and radiative forcing, Atmos. Environ., 40, 6465-6476, 2006.

Marín, M. J., Sola, Y., Tena, F., Utrillas, M. P., Campmany, E., de Cabo, X., Lorente, J., and Martínez-Lozano, J. A.: The UV index on the Spanish Mediterranean Coast, Photochem. Photobiol., 81, 659-665, 2005.

Martínez-Lozano, J. A., Tena, F., and Marín, M. J.: UV index experimental values during the years 2000 and 2001 from the Spanish Broadband UVB radiometric network, Photochem. Photobiol., 76, 181-187, 2002.

Mayer, B. and Kylling, A.: Technical note: The libRadtran software package for radiative transfer calculations - description and examples of use, Atmos. Chem. Phys., 5, 1855-1877, doi:10.5194/acp-5-1855-2005, 2005.

Mayer, B., Seckmeyer, G., and Kylling, A.: Systematic longterm comparison of spectral UV measurements and UVSPEC modelling results, J. Geophys. Res., 102, 8755-8767, 1997.

McKinlay, A. F. and Diffey, B. L.: A reference spectrum for ultraviolet induced erythema in human skin, CIE J., 6, 21-27, 1987.

Nunez, M., Michael, K., Turner, D., Wall, M., and Nilsson, C.: A satellite-based climatology of UV-B irradiance for antarctic coastal regions, Int. J. Climatol., 17, 1029-1054, 1997.

Shettle, E. P.: Models of aerosols, clouds and precipitation for atmospheric propagation studies, in: AGARD Conference Proceedings No. 454, Atmospheric propagation in the uv, visible, ir and mm-region and related system aspects, Advisory Group for Aerospace Research and Development (AGARD), Brussels, Belgium, 1989.

UNEP - United Nations Environment Programme: United Nations Environmental Programme: Environmental effects of ozone depletion and its interactions with climate change: 2006 assessment, Tech. Rep., UNEP, Nairobi, Kenya, 2006.

Vanicek, K., Frei, T., Lytinska, Z., and Schmalwieser, A.: UV-index for the Public, Report of the COST-713 Action, European Commission, Brussels, Belgium, 2000.

Vilaplana, J. M.: Measurement and analysis of ozone and UV solar radiation at El Arenosillo-INTA (Huelva, Spain), Ph.D. thesis, Universidad de Valladolid, Valladolid, Spain, 247 pp., 2004.

Vilaplana, J. M., Cachorro, V. E., Sorribas, M., Luccini, E., de Frutos, A., Berjón, A., and de la Morena, B.: Modified calibration procedures for a Yankee Environmental System UVB-1 biometer based on spectral measurements with a Brewer spectrophotometer, Photochem. Photobiol., 82, 508-514, 2006.

Vilaplana, J. M., Serrano, A., Antón, M., Cancillo, M. L., Parias, M., Gröbner, J., Hulsen, G., Zablocky, G., Díaz, A., and de la Morena, B. A.: Report of the El Arenosillo/INTA-COST calibration an intercomparison campaign of UVER broadband radiometers, "El Arenosillo", Huelva, Spain, August-September 2007, available at: http://www-med-physik.vu-wien.ac.at/uv/ COST726/COST726_Dateien/Results/Report_El_Arenosillo.pdf, last access: 1 June 2010, ISBN: 978-84-692-2640-7, COST Office, 64 pp., 2009.

Webb, A. and Holick, M.: The role of sunlight in the cutaneous production of vitamin D3, Annu. Rev. Nutr., 8, 375-399, 1998.

Webb, A., Gardiner, B., Leszczynski, K., Mohnen, V., Johnston, P., Harrison, N., and Bigelow, D.: Quality assurance in monitoring solar ultraviolet radiation: The state of the art, Tech. Rep. 146, World Meteorological Organization, Geneva, Switzerland, 2003.

Webb, A., Gröbner, J., and Blumthaler, M.: A Practical Guide to Operating Broadband Instruments Measuring Erythemally Weighted Irradiance, Office for Official Publications of the European Communities, Brussels, Belgium, ISBN: 92-898-0032-1, 21 pp., 2006.

WHO - World Health Organization: Global solar UV index: A practical guide, WHO/SDE/OEH/02.2, WHO, Geneva, Switzerland, 2002.

WMO - World Meteorological Organization: WMO-UMAP workshop on broadband UV radiometers, Tech. Rep. 120, WMO/Global Atmosphere Watch, Geneva, Switzerland, 1996.

WMO - World Meteorological Organization: Report of the WMOWHO meeting of experts on standardization of UV indices and their dissemination to the public, Les Diablerets, Switzerland, 21-24 July 1997, Tech. Rep. 127, WMO/Global Atmosphere Watch, Geneva, Switzerland, 1998. 